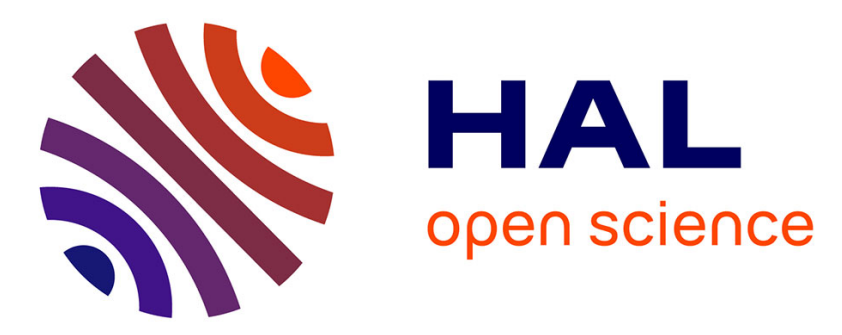

\title{
From Monolayer to Multilayer: Perylenediimide Diazonium Derivative Acting Either as a Growth Inhibitor or a Growth Enhancer
}

Viacheslav Shkirskiy, Julien Billon, Eric Levillain, Christelle Gautier

\section{To cite this version:}

Viacheslav Shkirskiy, Julien Billon, Eric Levillain, Christelle Gautier. From Monolayer to Multilayer: Perylenediimide Diazonium Derivative Acting Either as a Growth Inhibitor or a Growth Enhancer. Langmuir, 2021, 37 (44), pp.12834-12841. 10.1021/acs.langmuir.1c01808 • hal-03432315

\section{HAL Id: hal-03432315 \\ https://univ-angers.hal.science/hal-03432315}

Submitted on 22 Nov 2021

HAL is a multi-disciplinary open access archive for the deposit and dissemination of scientific research documents, whether they are published or not. The documents may come from teaching and research institutions in France or abroad, or from public or private research centers.
L'archive ouverte pluridisciplinaire HAL, est destinée au dépôt et à la diffusion de documents scientifiques de niveau recherche, publiés ou non, émanant des établissements d'enseignement et de recherche français ou étrangers, des laboratoires publics ou privés. 


\section{From monolayer to multilayer:}

\section{perylenediimide diazonium derivative acting either}

\section{as growth inhibitor or growth enhancer}

Viacheslav Shkirskiy*, Julien Billon, Eric Levillain, Christelle Gautier*

MOLTECH-Anjou, Université D'Angers, UMR CNRS 6200, 2 Boulevard Lavoisier, 49045

Angers, France

Corresponding authors: slava.shkirskiy@gmail.com, christelle.gautier@univ-angers.fr

Keywords: surface functionalization, aryldiazonium salts, controlled electrografting, perylenediimide 


\begin{abstract}
Fine control of electrografting kinetics of diazonium salts is of paramount importance, particularly when considering application of diazoniums for fabrication of 2D nanomaterials. In this work, we develop on controlled grafting of perylenediimide (PDI) moiety separated with a 12-carbon aliphatic chain from aryldiazonium. The particular design of the diazonium cation synthesized for this study allows fine-tuning of the surface coverage by simple adjustment of the applied potential. Indeed, according to the potential imposed at the working electrode, the PDI moiety can either enhance the charge propagation within the growing layer or consume the diazonium salt in the bulk solution via redox cross-reaction. With this approach, the surface functionalization can be restricted to a monolayer or a multilayer in a robust and elegant manner, obeying Langmuir or first-order kinetics of electrografting, respectively. The experimental observations are supported with in-situ spectroelectrochemical investigations aimed to differentiate reduction of PDI moieties in the deposited layer and the bulk solution. Tentative mechanistic scheme is proposed and numerical simulations are undertaken to rationalize the data.
\end{abstract}




\section{Introduction}

Grafting of diazonium salts is widely used for the tailored modification of conductive interfaces properties as it allows a covalent attachment of a wide range of electrochemically active moieties to any type of substrate. ${ }^{1,2}$ This has already been proven to be a very powerful approach in a wide range of practical applications such as corrosion, ${ }^{3}$ sensing, ${ }^{4}$ electrocatalysis, ${ }^{5}$ energy storage ${ }^{6}$ and others. ${ }^{1,7} \mathrm{Up}$ to the present day, the main drawback of diazonium grafting still remains a poor control of the deposited layer thickness due to the high reactivity of generated aryl radical species. ${ }^{1,2}$ This puts serious constrains on the fabrication of 2Dnanomaterials via electrochemical grafting where a fine control of deposition kinetics is required.

A few strategies have been proposed in an effort to overcome this issue. For example, it was shown that hindering 3,5-positions of the diazonium with chemically inert tert-butyl ${ }^{8,9}$ groups prevents anchoring of aryl radicals to already grafted aryl groups, significantly inhibiting grafting of multilayers. Some authors also used calix[4]arene ${ }^{10}$ or $3 \mathrm{D} \mathrm{Ru}(\mathrm{II})^{11}$ based moieties, which protected the grafted layers from the attack of aryl radicals and additionally led to the self-organization of the layer structure. Another group of methods was based on the degradation of preformed multilayers rather than on controlling the grafting kinetics via diazonium modifications. In this way, monolayers of thiophenolate ${ }^{12}$ and benzaldehyde ${ }^{13}$ were obtained from grafting of diazoniums with cleavable disulfide and hydrazine groups. Although very successful, mentioned approaches cannot be translated to grafting of any diazonium compound and are hardly compatible with the introduction of any functional group since the use of specific organic moieties is required.

Against this background, a more universal approach has been suggested based on the addition of a cross-redox inhibitor to a reactive mixture of any diazonium. ${ }^{14-17}$ The formation of 4-nitrobenzene (NB) layers was significantly limited in the presence of 2,2- 
diphenylpicrylhydrazyl (DPPH) redox mediator at $-0.5 \mathrm{~V}$ vs $\mathrm{Ag} / \mathrm{AgNO}_{3}$ (all further potentials are quoted vs $\left.\mathrm{Ag} / \mathrm{AgNO}_{3}\right){ }^{14,15}$ Chronoamperometric grafting demonstrated that the surface coverage of NB layers drops drastically to a monolayer after a threshold potential of $0 \mathrm{~V}$, which was coherent with the onset of DPPH reduction. ${ }^{15,17}$ Further chronoamperometric studies on the NB layer formation in aerated acetonitrile (ACN) solvent without DPPH showed that the decrease of NB surface coverage was equally observed after ca. $-0.6 \mathrm{~V} .{ }^{16}$ In this case, the potential threshold coincided with the onset of oxygen reduction. The suggested mechanism of inhibition of multilayer formation included the reduction of diazonium salt in the bulk solution with the reduced form of the redox mediator $\left(\mathrm{DPPH}^{-}\right.$or $\left.\mathrm{O}_{2}{ }^{--}\right){ }^{17}$

Herein we take a further step towards developing new approaches for a fine control of the grafting kinetics via incorporation of a redox mediator (perylenediimide - PDI derivative) directly into the diazonium molecule (Fig. 1). Moreover, the presence of a redox group in a grafted layer can render the deposited layer conductive and favor formation of thick multilayers as shown with 4-nitrobenzenediazonium, 4-benzoylbenzenediazonium and 9,10-dioxo-9,10dihydroanthracene-2-diazonium. ${ }^{18}$ Therefore, we anticipate the opposite effects generated by a PDI group, resulting in either inhibition via a cross-redox reaction or acceleration of multilayer formation via a facilitation of radical formation due to enhanced heterogeneous electron transfer. Given the above background, the primary goal of this work was to investigate the kinetics of diazonium layer formation composed of a redox group, using PDI moiety as a typical system. The PDI and aryl groups were separated with an inert aliphatic chain (12 atoms) to suppress their electronic interaction and thus, preserve the reduction properties of individual moieties. 


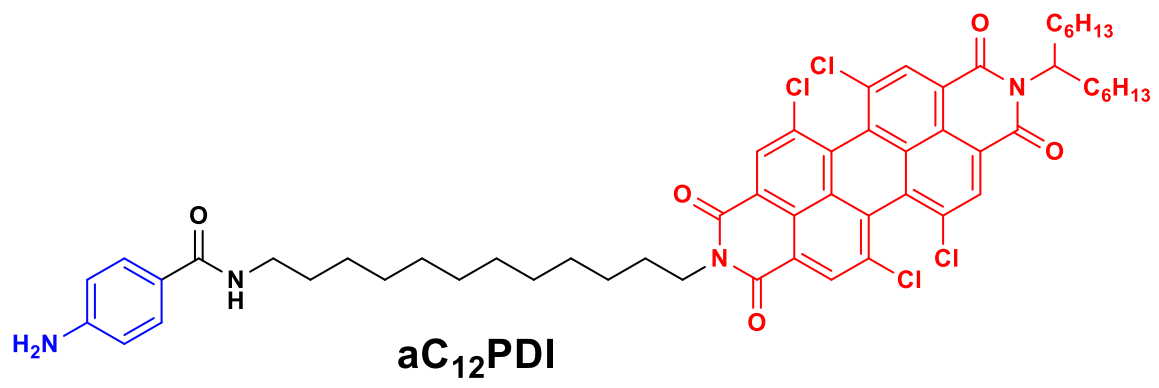

Figure 1. Structure of the amine used for in-situ grafting, the molecule denoted as $a C_{12} P D I . T h e$ molecule consists of PDI (in red) and aniline (in blue) derivatives connected through an aliphatic 12-carbon chain. See Supplementary Information (SI-1) for details about synthesis.

\section{Experimental section}

\section{Materials and reagents}

The $a C_{12} P D I$ compound was synthetized by a two-step procedure described in detail in SI-1. The final product $a C_{12} P D I$ was purified in silica gel column chromatography and used for in-situ generation of diazonium salts, further called $\mathrm{dC}_{12} \mathrm{PDI}$. Tetrabutylammonium hexafluorophosphate $\left(\mathrm{TBAPF}_{6}\right.$ - Sigma-Aldrich), dichloromethane (DCM - HPLC grade, VWR chemicals), acetonitrile (ACN-HPLC grade, Carlo Erba), tert-Butyl nitrite (tBuONO Sigma-Aldrich) were used as received. Milli-Q water $(18 \mathrm{M} \Omega \times \mathrm{cm})$ was used during polishing and for rinsing of the electrodes. A circular glassy carbon (GC) electrode was supplied by Bioanalytical Systems Inc. (Model MF-2012 with a surface area of $0.07 \mathrm{~cm}^{2}$ ).

\section{Electrochemical grafting}

Prior to each experiment, the surface of GC working electrode was polished with a 0.04 $\mu \mathrm{m} \mathrm{Al}_{2} \mathrm{O}_{3}$ slurry (PRESI), sonicated in water and DCM for 2 min and rinsed with DCM. A BioLogic potentiostat (VSP model with 4 channels) was employed to carry out all electrochemical experiments. Electrochemical grafting was performed in a 3-electrode cell with 
$2 \mathrm{ml}$ of $0.1 \mathrm{M} \mathrm{TBAPF}_{6} \mathrm{DCM}$ stagnant solution with $1 \mathrm{mM}$ of $\mathrm{aC}_{12} \mathrm{PDI}$. Five equivalents of tBuONO were added into solutions and stirred for $10 \mathrm{~min}$ before imposing the grafting potential or the potential sweep for the in-situ generation of $\mathrm{dC}_{12} \mathrm{PDI}$ from amine as described in literature. ${ }^{19}$ Note that the $\mathrm{BuONO}$ compound is not electrochemically active (SI-2) and does not contribute to the electrochemical response. A Pt rod was used as a counter electrode and a $\mathrm{Ag} / \mathrm{AgNO}_{3}\left(0.01 \mathrm{M}\right.$ in $\left.0.1 \mathrm{M} \mathrm{TBAPF}_{6} \mathrm{ACN}\right)$ was used as a reference electrode. An AC frequency of $10 \mathrm{kHz}$ with $30 \mathrm{mV}$ peak-to-peak amplitude was imposed on DC potential during chronoamperometric grafting experiments to follow evolution of capacitive impedance. Then, the capacitive impedance values were converted into surface coverage values from the calibration curves, providing kinetics of grafting as described in detail in ref. ${ }^{20}$ and SI-3.

After the deposition of $\mathrm{C}_{12} \mathrm{PDI}$ layer, the $\mathrm{GC}$ electrodes were sonicated for $2 \mathrm{~min}$ and washed with DCM. The surface coverage of PDI electroactive groups was estimated from cyclic

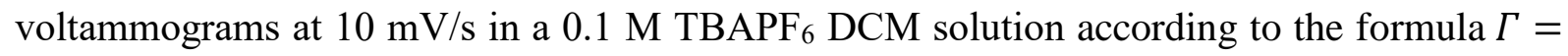
$Q / n F S$, where $\Gamma$ is the surface coverage, $Q$ is the charge estimated by integration of reduction peaks in $\mathrm{CV}, n=2$ is the number of electrons involved, $F=96485 \mathrm{C} / \mathrm{mol}$ is the Faraday constant and $S=0.07 \mathrm{~cm}^{2}$ is the surface area of electrode.

All experiments with potential imposed more negative than $-0.5 \mathrm{~V}$ were carried out in a glovebox $\left(\mathrm{O}_{2}<100 \mathrm{vpm}\right.$ and $\left.\mathrm{H}_{2} \mathrm{O}<10 \mathrm{vpm}\right)$ to avoid any interference of oxygen reduction process. All experiments were performed at room temperature of ca. $290 \mathrm{~K}$.

\section{Spectroelectrochemical characterization}

Spectrophotometric measurements were carried out in a reflection mode using an inhouse made bench composed of Princeton Instruments modules coupled to Biologic SP-150 potentiostat. Details of the instrumentation can be found elsewhere. ${ }^{21,22}$ In short, a 3-electrode cell with GC as working electrode, $\mathrm{Pt}$ as counter electrode and $\mathrm{Ag} / \mathrm{AgNO}_{3}(0.01 \mathrm{M}$ in $0.1 \mathrm{M}$ 
$\mathrm{TBAPF}_{6} \mathrm{ACN}$ ) as reference electrode (identical to electrochemical grafting) were employed. The connection between the light source, the electrochemical cell and the spectrophotometer was ensured through a "Y-shaped" optical fiber bundle: 18 fibers to guide the light to the cell, and 19 fibers to collect the reflected light from the cell directing it to the CDD detector (320$1080 \mathrm{~nm}, 0.5 \mathrm{~nm}$ spectral resolution, $2 \mathrm{MHz}$ acquisition bandwidth). The acquisition rate of spectrometer was set to 10 frames per second that converted to 1 frame per $\mathrm{mV}$ at $10 \mathrm{mV} / \mathrm{s}$.

EC-Lab software was used to control the BioLogic potentiostat and trigger the acquisition of spectral data, which guaranteed identical time scales of two independent measurements. In-house-built software was used for data plotting and processing. For each dataset, the reference intensity $\left(I_{r e f}\right)$ was obtained by averaging the intensity of the first 10 measured frames. Consequently, an absorbance variation $(\Delta \mathrm{Abs})$ and not an absorbance value (Abs) was monitored:

$$
\Delta \mathrm{Abs}=\mathrm{Abs}-\mathrm{Abs}_{\text {ref }}=-\log _{10}\left(I / I_{\text {ref }}\right)
$$

\section{Numerical simulations}

The numerical simulations were carried out using KISSA-1D ${ }^{\odot}$ software, version 1.2.2b..$^{23,24}$ The Butler-Volmer relationship was used to describe all electrochemical reactions. The monolayer formation was described with the Langmuir isotherm. The formation of multilayers was described with a first-order adsorption kinetics achieved by setting the saturation surface coverage for the Langmuir isotherm in KISSA-1D ${ }^{\odot}$ software $10^{5}$ times larger in comparison to the value for the monolayer (vide infra). Simulations were performed for a planar electrode of $0.07 \mathrm{~cm}^{2}$ under natural convection conditions with a stagnant layer thickness of $250 \mu \mathrm{m}$. Diffusion coefficients of all species were $5 \times 10^{-6} \mathrm{~cm}^{2} \mathrm{~s}^{-1}$. The values of equilibrium potentials, kinetic constants, charge transfer coefficients and surface coverage at saturation are 
summarized in Table 1. We also provide all technical details of KISSA-1D ${ }^{\odot}$ simulations in SI5.

\section{Results and Discussion}

\section{Overview of $d C_{12} P D I$ reduction}

We performed the cycling voltammetry of $\mathrm{aC}_{12} \mathrm{PDI}$ and in-situ generated $\mathrm{dC}_{12} \mathrm{PDI}$ compounds in a large potential window to identify the onset potentials and reduction kinetics of PDI derivatives and diazonium salt.

Fig. 2a shows a typical voltammogram of $\mathrm{aC}_{12} \mathrm{PDI}$ compound. On the cathodic sweep, the current is close to zero from $0.8 \mathrm{~V}$ to ca. $-0.55 \mathrm{~V}$ then decreases showing two reduction peaks with later slight increase, reaching the diffusion-limited current of $-50 \mu \mathrm{A} \mathrm{cm}^{-2}$ at $-1.3 \mathrm{~V}$. Two oxidation peaks appear on the reverse scan with current gradually dropping to zero from ca. $-0.55 \mathrm{~V}$ to $0.8 \mathrm{~V}$. The half-way potentials for the first and the second reduction/oxidation steps are $-0.66 \mathrm{~V}$ and $-0.86 \mathrm{~V}$ correspondingly. In both cases, the peak-to-peak separation is ca. $80 \mathrm{mV}$, indicating the fast electron transfer typical for PDI derivatives. ${ }^{25,26}$

The shape of voltammogram changes when the formation of $\mathrm{dC}_{12} \mathrm{PDI}$ is initiated by addition of $\mathrm{tBuONO}$ in the solution of $\mathrm{aC}_{12} \mathrm{PDI}$ (Fig. 2b). The two peaks, associated with the reversible reduction of PDI group, remain present in Fig. 2b. The position of these peaks and the peak-to-peak separation are identical to the ones observed on the voltammogram recorded on $\mathrm{aC}_{12} \mathrm{PDI}$ compound in Fig. 2a. The absolute values of currents associated with PDI reduction and oxidation increase with cycling. Apart from the response of the PDI group, a slight decrease of the cathodic current at ca. $0.25 \mathrm{~V}$ is observed, reaching a plateau of ca. $-2.5 \mu \mathrm{A} \mathrm{cm}^{-2}$ between $0.05 \mathrm{~V}$ to $-0.3 \mathrm{~V}$ (Fig. $2 \mathrm{~b}$ inset) that is associated with the reduction of diazonium moiety. ${ }^{1}$ This current drop is apparent only on the first cycle suggesting the suppression of diazonium reduction after the initial $\mathrm{C}_{12} \mathrm{PDI}$ layer was formed. 
Another new distinct feature is the appearance of the reduction peak at ca. $-0.45 \mathrm{~V}$ with the current reaching of ca. $-30 \mu \mathrm{A} \mathrm{cm}^{-2}$. The position of this peak slightly shifts to more negative potentials with a slight increase of the reduction current on the consequent scans. Remarkably, on the anodic scans the current drops down to a negative value of ca. $-7 \mu \mathrm{A} \mathrm{cm}^{-2}$ at ca. $-0.45 \mathrm{~V}$, indicating a reduction process ongoing in this region. The origin of this peak is not clear. Note that the voltammogram recorded on $\mathrm{C}_{12} \mathrm{PDI}$ layer (Fig. 2c) shows minor contribution of grafted PDI moieties to current density at $-0.45 \mathrm{~V}$ in Fig. $2 \mathrm{~b}$. The position of reduction/oxidation peaks (Fig. 2c) lies more negative than $-0.45 \mathrm{~V}$ and is similar to half-way potentials of $\mathrm{aC}_{12} \mathrm{PDI}$ in Fig. 2a.

Below, we also provide experiments on the grafting at fixed potential as well as spectroelectrochemical studies to clarify the origin of the peak at $-0.45 \mathrm{~V}$ in Fig. $2 \mathrm{~b}$ and the mechanisms of $\mathrm{C}_{12} \mathrm{PDI}$ layers formation. 

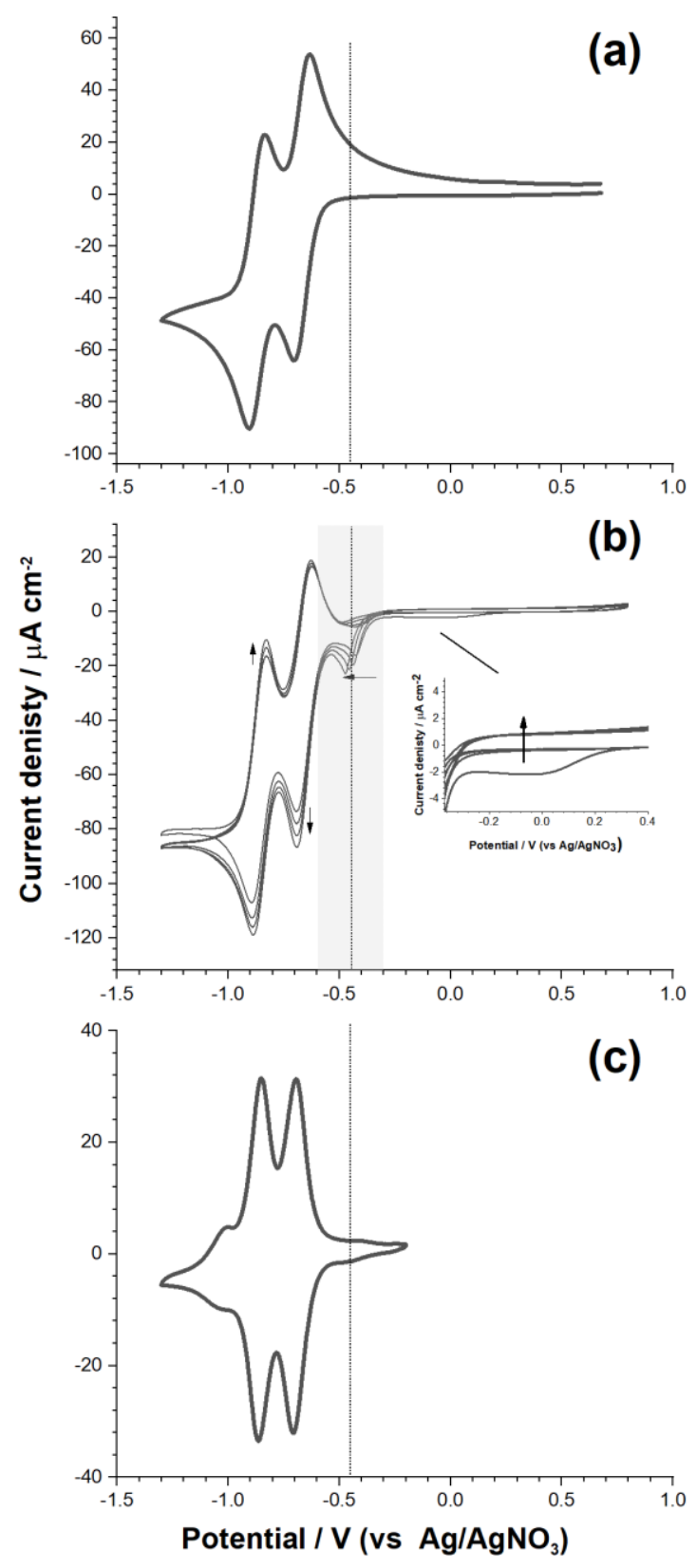

Figure 2. (a) Cyclic voltammograms of (a) $1 \mathrm{mM} a C_{12} P D I$, (b) $1 \mathrm{mM} a C_{12} P D I+5$ eq. of tBuONO and (c) grafted $C_{12} P D I$ layer formed after 3 polarization cycles in figure (b) with a surface coverage of $24 \times 10^{-10} \mathrm{~mol} \mathrm{~cm}^{-2}$. Experiments were performed on GC in a $0.1 \mathrm{MTBAPF_{6 }}$ DCM solution in a glovebox. The potential sweeps start at the most positive potential, progresses towards $-1.3 \mathrm{~V}$ and returns to the initial potential at $10 \mathrm{mV} / \mathrm{s}$. The dotted lines are placed at the fixed potential of -0.45 V and semitransparent grey box covers the potential range of -0.3 to -0.6 V for the visual reference. 


\section{Surface coverage of $C_{12}$ PDI layer as a function of applied potential}

Evolution of the surface coverage of $\mathrm{C}_{12} \mathrm{PDI}$ layers formed on $\mathrm{GC}$ under applied potential in Fig. 3a shows 4 distinct regions.

In the $1^{\text {st }}$ region, ranging from $0.3 \mathrm{~V}$ to $0.8 \mathrm{~V}$, the surface coverage is close to zero and no grafting occurs.

At ca. $0.25 \mathrm{~V}$, the grafting starts with $\Gamma=1.2 \times 10^{-10} \mathrm{~mol} \mathrm{~cm}^{-2}$ after $15 \mathrm{~min}$ of grafting and $\Gamma=2.4 \times 10^{-10} \mathrm{~mol} \mathrm{~cm}^{-2}$ after 30 min of grafting. As the potential decreases down to $-0.3 \mathrm{~V}$, the surface coverage gradually increases up to $\Gamma=3.0 \times 10^{-10} \mathrm{~mol} \mathrm{~cm}^{-2}$ for both, $15 \mathrm{~min}$ and 30 min of grafting. This value is close to the surface coverages observed for PDI-based SAMs ${ }^{25}$ suggesting the formation of $\mathrm{C}_{12} \mathrm{PDI}$ monolayers. Kinetics of layer grafting in the region of -0.3 $\mathrm{V}-+0.25 \mathrm{~V}$ shows a Langmuir type behavior (Fig. 3b, curve at $0 \mathrm{~V}$ ) with a rapid increase of surface coverage during initial 100 - $200 \mathrm{~s}$, followed by the gradual transition to a steady-state value of ca. $3.0 \times 10^{-10} \mathrm{~mol} \mathrm{~cm}^{-2}$. Importantly, the surface coverage did not exceed this value, even after $2 \mathrm{~h}$ grafting at $0 \mathrm{~V}$ which is not the case for grafting of other diazonium salts of benzene derivatives (nitrobenzene, carboxybenzene etc) ${ }^{27-29}$. Conventionally, a grafting of multilayers for mentioned molecules is explained by slow electron transfer through grafted layer, reduction of aryl diazonium to aryl radical and its grafting on the preformed layer. ${ }^{27}$ The key difference between mentioned benzene derivatives and $\mathrm{dC}_{12} \mathrm{PDI}$ compound is the presence of the aliphatic 12-carbon chain, which supposedly blocks completely the electron transfer via $\mathrm{C}_{12} \mathrm{PDI}$ monolayer and prevents the diazonium reduction and multilayer formation. ${ }^{30}$

The $3^{\text {rd }}$ region covers the potential range between $-0.35 \mathrm{~V}$ and $-0.55 \mathrm{~V}$ where the surface coverage significantly overpasses the characteristic value of a monolayer, reaching the maximum at ca. $-0.4 \mathrm{~V}$. Remarkably, this region coincides with the extension of peak at ca. $-0.45 \mathrm{~V}$ in Fig. 2 b, marked with a semitransparent grey box. The absolute values of surface 
coverage depend on the grafting time. For example, at $-0.4 \mathrm{~V}, \Gamma$ equals $36 \times 10^{-10} \mathrm{~mol} \mathrm{~cm}^{-2}$ after $15 \mathrm{~min}$ of grafting and it increases to $62 \times 10^{-10} \mathrm{~mol} \mathrm{~cm}^{-2}$ after $30 \mathrm{~min}$ of grafting. We also performed a $2 \mathrm{~h}$ long experiment at $-0.4 \mathrm{~V}$ and were able to reach $\Gamma=10^{-8} \mathrm{~mol} \mathrm{~cm}^{-2}$. In contrast to the Langmuir type kinetics at $0 \mathrm{~V}$, the surface coverage increases linearly with time in this region, as illustrated on the example of grafting at $-0.5 \mathrm{~V}$ in Fig. 3b, demonstrating a first order kinetics.

All these experimental observations suggest that, despite the presence of a 12-carbon chain separator between the PDI moiety and the phenyl group, the $\mathrm{C}_{12} \mathrm{PDI}$ layer supports the diazonium reduction in the potential range of $-0.35 \mathrm{~V}$ and $-0.55 \mathrm{~V}$ in contrast to $-0.3 \mathrm{~V}-+0.25$ V. The previous studies on grafted nitrobenzene-, benzoylbenzene- and polyphenylenelayers $^{18,31}$ reported that the reduction of deposited layers promotes electron transfer via the tunnel effect through organic layer, ${ }^{30}$ that can be the case of the $\mathrm{C}_{12} \mathrm{PDI}$ layer too. The survey of the redox state of $\mathrm{C}_{12} \mathrm{PDI}$ layer will be performed in the next section.

At potentials more negative than $-0.6 \mathrm{~V}$, the surface coverage abruptly drops to values close to zero (Fig. 3a), coherent with grafting kinetics in Fig. 3b. Similar effect of surface coverage decrease at cathodic overpotentials was observed by adding redox mediators in the grafting solution $\left(\mathrm{DPPH}^{14}\right.$ and $\left.\mathrm{O}_{2}{ }^{16}\right)$. In our case, the only redox mediator present in the solution is the PDI entity of $\mathrm{aC}_{12} \mathrm{PDI}$ and $\mathrm{dC}_{12} \mathrm{PDI}$ molecules. Seemingly, the subtle differences in the reduction kinetics of PDI moieties present in the solution and grafted on GC interface play a crucial role in the mechanisms of diazonium grafting. In the next section, we provide comparative spectroelectrochemical study to unravel these effects. 

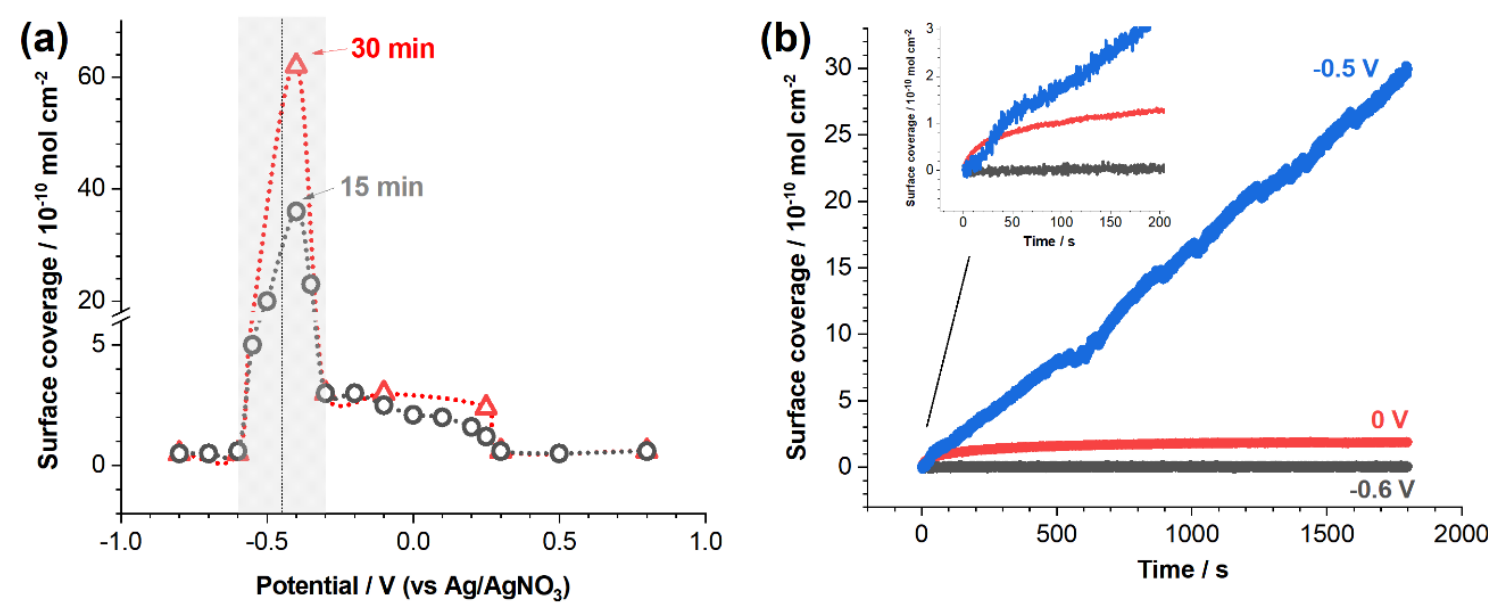

Figure 3. (a) Surface coverage of $C_{12} P D I$ layers as a function of applied potential during electrodeposition. The potential was imposed for $15 \mathrm{~min}$ (grey circles) and $30 \mathrm{~min}$ (red triangles) using GC working electrode and $1 \mathrm{mMa} C_{12} P D I+5 e q$. of $t B u O N O$ in $0.1 M T B A P F_{6}$ DCM. The dotted line is placed at the fixed potential of -0.45 V and semitransparent grey box covers the potential range of -0.3 to $-0.6 \mathrm{~V}$ for the visual reference. (b) Surface coverage vs time defined from in-situ capacitive measurements ${ }^{20}$ at fixed potentials of $0 \mathrm{~V},-0.5 \mathrm{~V}$ and -0.6 $V$. All experiments at potentials more negative than $-0.5 V$ were performed in a glovebox.

\section{Reduction states of PDI moieties in solution and in $C_{12}$ PDI layer as a function of potential}

Fig. 4 shows the evolution of relative absorbance of PDI moiety in the grafted $\mathrm{C}_{12} \mathrm{PDI}$ layer on GC during a polarization cycle. The voltage ramp ( $\mathrm{Y}$ axis) starts at $-0.2 \mathrm{~V}$ then it progresses towards $-1.3 \mathrm{~V}$ (horizontal blue line in Fig. 4) and returns to the initial potential of $0.2 \mathrm{~V}$. The axial symmetry along a $-1.3 \mathrm{~V}$ line implies that the changes of the electronic structure of PDI moiety are reversible and do not depend on the direction of polarization. For this reason, we consider only the bottom part of spectral signature that shows the first part of the polarization cycle from $-0.2 \mathrm{~V}$ to $-1.3 \mathrm{~V}$. Note that $\Delta \mathrm{Abs}$ values $\left(\Delta \mathrm{Abs}=\mathrm{Abs}-\mathrm{Abs}_{\mathrm{ref}}\right.$, with $\mathrm{Abs}_{\mathrm{ref}}=$ absorbance recorded during the first 10 frames, see Eq. 1 in experimental section) are measured. Consequently, an electrochemical consumption of PDI moiety (band at $523 \mathrm{~nm}$ ) results in 
negative absorbance values and the generation of $\mathrm{PDI}^{-}($at $785 \mathrm{~nm})$ and $\mathrm{PDI}^{2-}($ at $693 \mathrm{~nm})$ from redox reaction leads to positive values of absorbance.

The subtle change of color in Fig. 4 of $\mathrm{PDI}^{-}$band from $-0.2 \mathrm{~V}$ to $-0.6 \mathrm{~V}$ indicates the onset of PDI reduction at ca. -0.4 (Fig. 4). This coincides with the decrease of current density, which, therefore, can be attributed to a faradaic process of $\mathrm{PDI}^{-}$formation. As potential decreases in Fig. 4, the values of PDI- ${ }^{-}$and $\mathrm{PDI}^{2-}$ absorbance start to increase coherent with the appearance of a second peak on current density curve. Remarkably, there is no variation in absorbance at ca. $-1.0 \mathrm{~V}$ where there is a small peak on the current density curve. This suggests that the source of current related to this peak is not related to faradaic processes of PDI reduction but probably is due to ion migration within the PDI layer ${ }^{18}$ and the layer reorganization due to the electrostatic repulsion between negatively charged $\mathrm{PDI}^{2-}$ groups etc.

Comparison of PDI moieties reduction (in solution and within the grafted layer) in Fig. 5 shows that the PDI in the bulk solution undergoes reduction at ca. $-0.55 \mathrm{~V}$, which is ca. $0.2 \mathrm{~V}$ more negative than PDI in the grafted layer. The potential window of selective PDI reduction in $\mathrm{C}_{12} \mathrm{PDI}$ layer is coherent with the potential window of multilayer formation in Fig. 3a and the extent of the peak at ca. $-0.4 \mathrm{~V}$ in voltammograms of $\mathrm{dC}_{12} \mathrm{PDI}$ compound in Fig. $2 \mathrm{~b}$ (highlighted with semitransparent grey box).

Overall, the correlation of spectroscopical and electrochemical results around $-0.45 \mathrm{~V}$ suggests that the reduction of deposited PDI moieties promotes tunnel effect through an organic layer and therefore, facilitates the electron transfer via the formed layer. In this vein, the peak in current density at $-0.45 \mathrm{~V}$ in Fig. $2 \mathrm{~b}$ corresponds to an enhanced reduction of diazoniums to aryl radicals. Once generated, highly reactive aryl radicals can chemically bond to $\mathrm{C}_{12} \mathrm{PDI}$ layer with the formation of multilayers. Below, we summarize the proposed reaction sequence in the whole potential range and provide numerical simulations to reinforce our findings. 


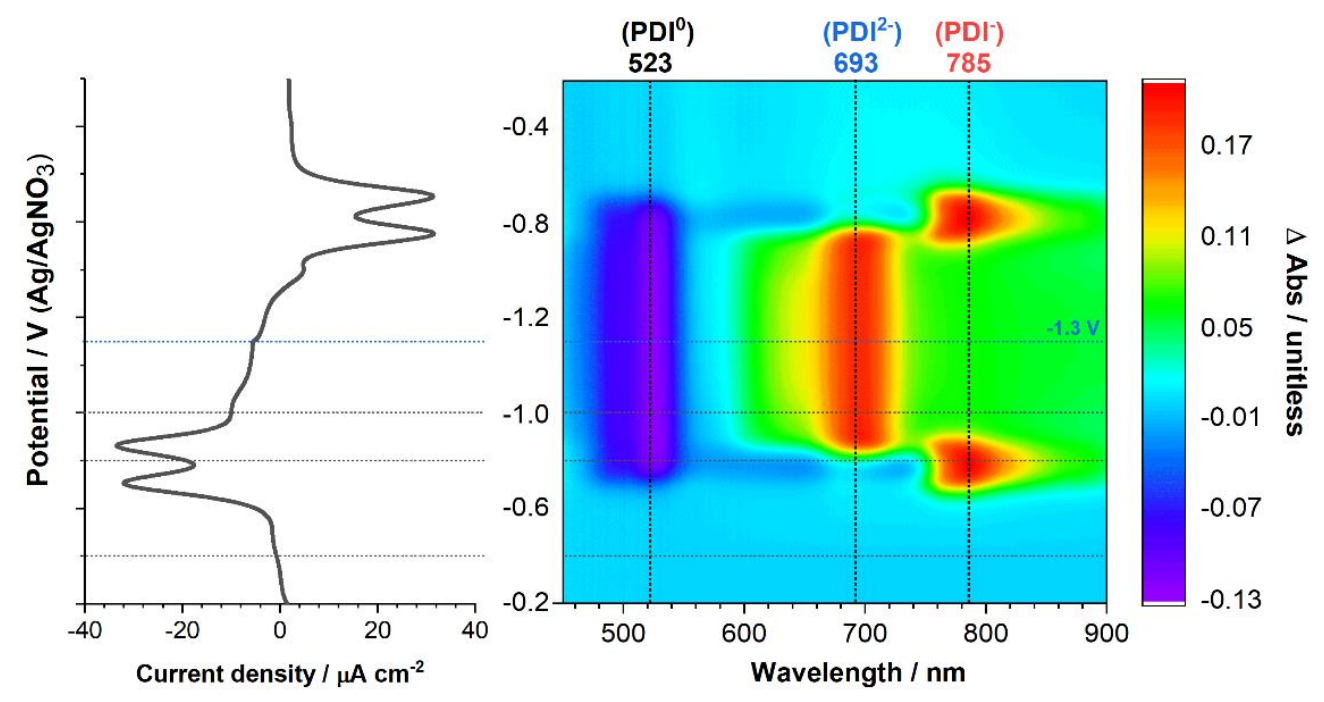

Figure 4. Absorbance variation (on the right) of grafted $C_{12} P D I$ layer on $G C\left(\Gamma=24 \times 10^{-10}\right.$

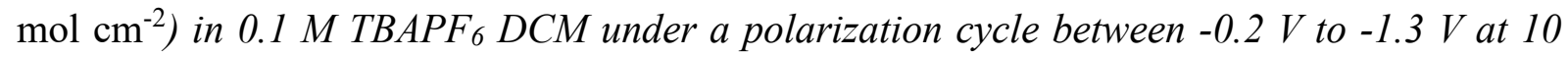
$\mathrm{mV} / \mathrm{s}$. The variation of simultaneously recorded current is presented on the left. The experiments were performed in a glovebox. The dotted lines indicate the bands positions attributed to the conversion of $P D I^{0}$ to $P D I^{-}$and $P D I^{2-}{ }^{25,26,32}$

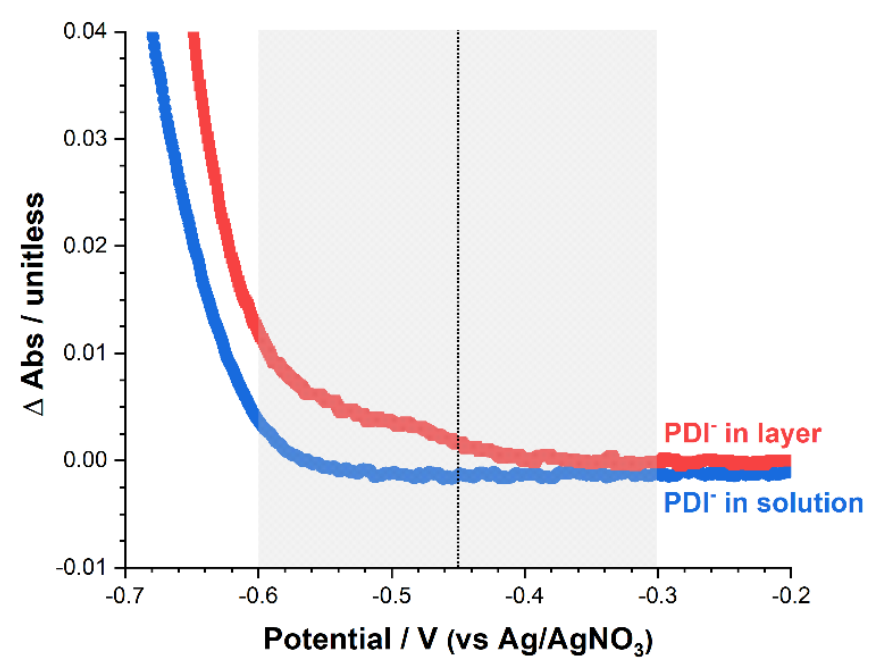

Figure 5. Comparison of absorption change values for PDI-- species in the grafted layer and under thin-layer conditions around the onset of PDI reduction. Details on experiment in the bulk solution are provided in SI-4. The dotted line is placed at the fixed potential of -0.45 V and semitransparent grey box covers the potential range of -0.3 to -0.6 V for the visual reference. 


\section{Tentative mechanism of $d C_{12} P D I$ grafting}

The exact mechanism of diazonium grafting that would encompass all aspects of deposition is still a subject of ongoing research, even in the case of a relatively simple and more studied NBD molecule. ${ }^{33,34}$ It is therefore not reasonable to propose a holistic mechanism of $\mathrm{dC}_{12} \mathrm{PDI}$ grafting but we rather focus on building the phenomenological model that would qualitatively describe the observed relationship between surface coverage, grafting kinetics and applied potential. Numerical simulations were carried out in Kissa-1D ${ }^{\odot}$ software (see Experimental section and SI-5 for details).

The electrografting process can be described by one-electron transfer reaction and two irreversible first order reactions: ${ }^{17,33,34}$ the reduction of diazonium $\left(\mathrm{dC}_{12} \mathrm{PDI}\right.$ noted as $\mathrm{N}_{2}^{+} \mathrm{Ar}-$ PDI) with the formation of aryl radical $(* \mathrm{Ar}-\mathrm{PDI} \text { ) (reaction } 1)^{35,36}$, followed by grafting of aryl radical to the GC surface with the formation of a covalent bond (reaction 2) ) $^{37,38}$ or consumption of highly reactive aryl radicals via side reactions involving solvent or other species (reaction 3). ${ }^{35,39}$ The diazonium reduction was considered irreversible in accordance with experimental data in this work.

$$
\begin{array}{lll}
\mathrm{N}_{2}^{+} \mathrm{Ar}-\mathrm{PDI}+e^{-} \rightarrow * \mathrm{Ar}-\mathrm{PDI}+\mathrm{N}_{2} & E_{1}^{0}, k_{1}^{0}, \alpha_{1} & \text { Reaction (1) } \\
* \mathrm{Ar}-\mathrm{PDI}+\mathrm{GC} \rightarrow \mathrm{GC}-\mathrm{Ar}-\mathrm{PDI} & k_{2}^{a d}, \Gamma_{2}^{s} & \text { Reaction (2) } \\
* \mathrm{Ar}-\mathrm{PDI} \rightarrow \text { side products } & k_{3}^{\text {ext }} & \text { Reaction (3) }
\end{array}
$$

The grafted layer undergoes reversible reduction at potentials lower than ca. $-0.4 \mathrm{~V}$. The deposition of non-reduced layer (reaction 2) follows Langmuir adsorption isotherm but as soon as the deposited layer is reduced, the formation of multilayers follows via enhancement of tunnel effect as discussed above. The multilayer growth is known to be a complex process that should at least depend on heterogeneous electron transfer rate that in turn depends on 
dynamically changing structure of deposited layer. ${ }^{33,34}$ For the sake of simplicity, we neglect these complex effects and consider the layer reduction ongoing via two reversible electron charge transfer in reactions 4 and 5. The formation of a multilayer was described with a first order kinetics, coherent with our experimental data (vide supra).

$$
\begin{array}{lr}
\mathrm{GC}-\mathrm{Ar}-\mathrm{PDI}+e^{-} \rightleftarrows \mathrm{GC}-\mathrm{Ar}-\mathrm{PDI}^{-} & E_{4}^{0}, k_{4}^{0}, \alpha_{4}, \Gamma_{4}^{s} \text { Reaction (4) } \\
\mathrm{GC}-\mathrm{Ar}-\mathrm{PDI}^{-}+e^{-} \rightleftarrows \mathrm{GC}-\mathrm{Ar}-\mathrm{PDI}^{2-} & E_{5}^{0}, k_{5}^{0}, \alpha_{5}, \Gamma_{5}^{s} \text { Reaction (5) }
\end{array}
$$

PDI moieties present in solution also undergo reduction with the onset potential of ca. $0.2 \mathrm{~V}$ more negative in comparison to grafted PDI groups. The source of PDI moieties can equally originate from $\mathrm{dC}_{12} \mathrm{PDI}, \mathrm{aC}_{12} \mathrm{PDI}$ or side products produced via reaction 3 . We do not make any distinction between these species, including all of them via reactions 6 and 7.

$$
\begin{array}{lll}
\mathrm{PDI}+e^{-} \rightleftarrows \mathrm{PDI}^{-} & E_{6}^{0}, k_{6}^{0}, \alpha_{6} & \text { Reaction (6) } \\
\mathrm{PDI}^{-}+e^{-} \rightleftarrows \mathrm{PDI}^{2-} & E_{7}^{0}, k_{7}^{0}, \alpha_{7} & \text { Reaction (7) }
\end{array}
$$

The key moment of the mechanistic scheme is the inclusion of irreversible crossreactions between reduced PDI moieties and diazonium compounds in the solution via reactions 8 and 9. Therefore, diazonium can be reduced in the bulk solution and resulting aryl radicals can be scavenged through formation in side products via reaction 3 . This restricts the concentration of aryl radicals in vicinity of GC interface and inhibits the layer deposition.

$$
\begin{array}{lll}
\mathrm{PDI}^{-}+\mathrm{N}_{2}^{+} \mathrm{Ar}-\mathrm{PDI} \rightarrow \mathrm{PDI}+* \mathrm{Ar}-\mathrm{PDI} & k_{8}^{f} & \text { Reaction (8) } \\
\mathrm{PDI}^{2-}+\mathrm{N}_{2}^{+} \mathrm{Ar}-\mathrm{PDI} \rightarrow \mathrm{PDI}^{-}+* \mathrm{Ar}-\mathrm{PDI} & k_{9}^{f} & \text { Reaction (9) }
\end{array}
$$

The input parameters for reactions 1-9 were either taken from literature or estimated from our experimental data and are summarized in Table 1. Results of numerical simulations are presented in Fig. 6. 

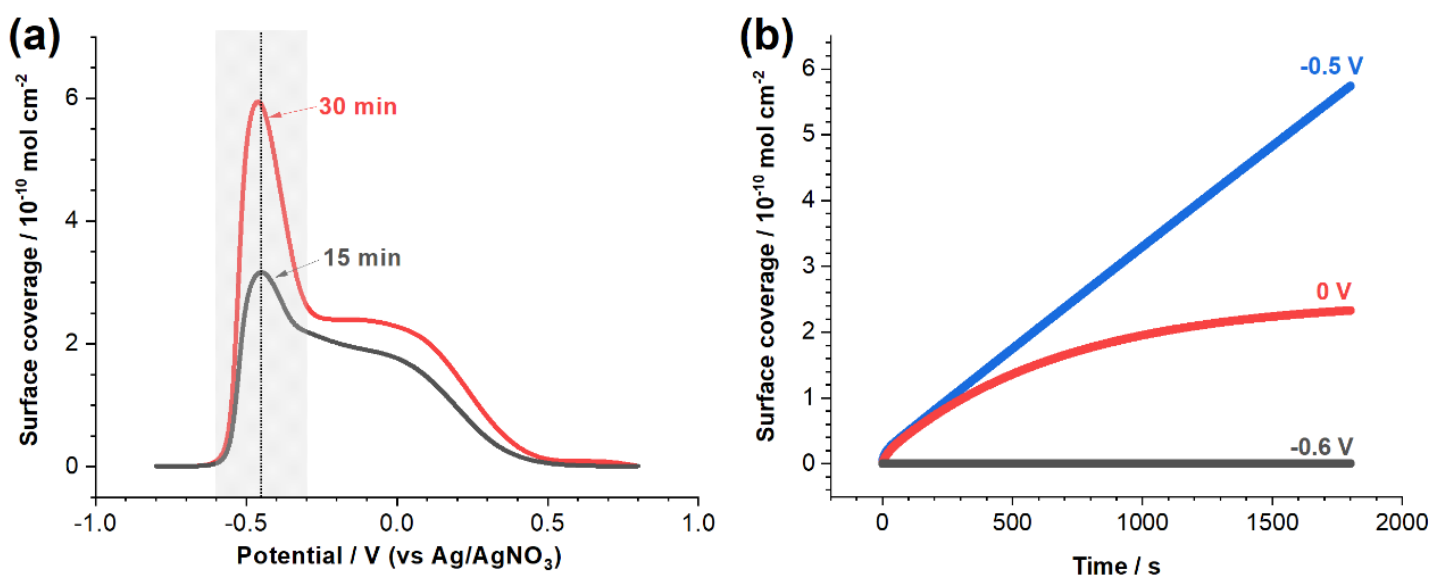

Figure 6. Results of numerical simulations in Kissa $1 D^{\odot}$ software of reactions 1-9 with input parameters in Table 1. (a) shows the surface coverage of deposited $C_{12}$ PDI layers as a function of applied potential. The potential was imposed for 15 min (grey curve) and 30 min (red curve). The dotted line is placed at the fixed potential of - $0.45 \mathrm{~V}$ and semitransparent grey box covers the potential range of -0.3 to $-0.6 V$ for the visual reference. (b) Surface coverage vs time at fixed potentials of $0 \mathrm{~V},-0.5 \mathrm{~V}$ and $-0.6 \mathrm{~V}$.

There is a good agreement between simulated and experimental data of surface coverage vs applied potential and grafting kinetics (compare Fig. 3 and Fig. 6). This validates the proposed mechanistic sequence and in particular the role of PDI moiety in first, favoring the formation of multilayer in a small potential window of ca. $-0.4 \mathrm{~V}$ to ca. $-0.6 \mathrm{~V}$ and second, inhibition of a layer deposition through cross-redox reactions at potentials lower than $-0.6 \mathrm{~V}$ in the bulk solution.

The biggest difference between experimental and simulated data concerns the absolute values of surface coverage related to the multilayer formation (marked with the semitransparent grey box). Obviously, this is related to the simplifications imposed on the model in terms of multilayer formation. Likewise, the structure of multilayer formation and its impact on heterogeneous electron transfer were not considered. Quantitative description of these effects 
requires detailed in-situ spectroelectrochemical characterization of $\mathrm{C}_{12} \mathrm{PDI}$ multilayers and will be the subject of our future work.

Table 1. Input parameters of numerical simulations where $E^{0}$ is the standard potential, $\alpha$ is the transfer coefficient, $\Gamma^{s}$ is the surface coverage at saturation and $k$ is the rate constant $\left(k^{0}-\right.$ standard electrochemical rate constant, $k^{\text {ad }}-$ adsorption rate constant, $k^{f}-$ forward rate constant). The reference is given for any value taken from the literature; otherwise, the values were estimated from experimental data in this work. The initial concentration of all species was zero except for $1 \mathrm{mM} \mathrm{N}_{2}^{+} \mathrm{Ar}-\mathrm{PDI}$ and $1 \mathrm{mM}$ PDI.

\begin{tabular}{|c|c|c|c|c|}
\hline Reaction & $\boldsymbol{E}^{\boldsymbol{0}}$ & $\boldsymbol{k}\left(k^{0}, k^{\text {ad }}\right.$ or $k^{\text {f }}$ & $\boldsymbol{\alpha}$ & $\boldsymbol{\Gamma}^{\boldsymbol{s}}$ \\
\hline 1 & $-0.10 \mathrm{~V}$ & $0.003 \mathrm{~cm} \mathrm{~s}^{-136}$ & $0.3^{36}$ & - \\
2 & - & $2 \times 10^{5} \mathrm{M}^{-1} \mathrm{~s}^{-1}$ & - & $2.5 \times 10^{-10} \mathrm{~mol} \mathrm{~cm}^{-2}$ \\
3 & - & $10^{8} \mathrm{~s}^{-135,39}$ & - & - \\
4 & $-0.40 \mathrm{~V}$ & $100 \mathrm{~s}^{-1}$ & 0.5 & $10^{-5} \mathrm{~mol} \mathrm{~cm}^{-2 *}$ \\
5 & $-0.60 \mathrm{~V}$ & $100 \mathrm{~s}^{-1}$ & 0.5 & $10^{-5} \mathrm{~mol} \mathrm{~cm}^{-2 *}$ \\
6 & $-0.66 \mathrm{~V}$ & $100 \mathrm{~cm} \mathrm{~s}^{-1}$ & 0.5 & - \\
7 & $-0.86 \mathrm{~V}$ & $100 \mathrm{~cm} \mathrm{~s}^{-1}$ & 0.5 & - \\
8 & - & $10^{8} \mathrm{~s}^{-117}$ & - & - \\
9 & - & $10^{8} \mathrm{~s}^{-117}$ & - & - \\
\hline
\end{tabular}

*The values of $\Gamma^{s}$ for multilayer formation were set to an arbitrary large value to provide a first order deposition kinetics in the Langmuir formalism uniquely available in KISSA-1D ${ }^{\odot}$ interface.

\section{Conclusion}

This study has elucidated the grafting mechanism of $\mathrm{dC}_{12} \mathrm{PDI}$ molecule as a function of applied potential. Three regimes, based on the difference in grafting kinetics have been 
highlighted for $\mathrm{C}_{12} \mathrm{PDI}$ layer formation. The first regime comprises grafting, which obeys Langmuir type kinetics and is restricted to the deposition of monolayers in the potential range above PDI moieties reduction. The second regime consists of grafting multilayers following the first order kinetics in the potential range restricted to the selective reduction of PDI moieties in the deposited layer (but not in the bulk solution). When species containing PDI groups undergo reduction in the solution, the deposition of $\mathrm{C}_{12} \mathrm{PDI}$ layer is strongly inhibited. The observed behavior was explained by the redox cross-reaction involving PDI reduced moieties in the bulk solution, and further reinforced with numerical modeling. This study demonstrates that the fine control of grafting kinetics of the redox active PDI moiety can be achieved through tuning the applied potential that, in principle, can be extended to any reducible active group.

\section{Supporting Information}

SI-1 Synthesis and characterization of $\mathrm{aC}_{12} \mathrm{PDI}$ compound; SI-2 Electrochemical response of tBuONO solution; SI-3 Methodology of in-situ estimation of surface coverages via capacitive impedance measurements; SI-4 Spectroelectrochemical signature of $\mathrm{aC}_{12} \mathrm{PDI}$ in the bulk solution; SI-5 Input parameters in KISSA-1DC interface (v. 1.2.2b).

\section{Acknowledgements}

The authors acknowledge the LUMOMAT funding program for a post-doctoral fellowship.

\section{References}

(1) Bélanger, D.; Pinson, J. Electrografting: A Powerful Method for Surface Modification. Chem. Soc. Rev. 2011, 40 (7), 3995-4048. https://doi.org/10.1039/c0cs00149j.

(2) Hapiot, P.; Lagrost, C.; Leroux, Y. R. Molecular Nano-Structuration of Carbon Surfaces through Reductive Diazonium Salts Grafting. Curr. Opin. Electrochem. 2018, 
7, 103-108. https://doi.org/10.1016/j.coelec.2017.11.003.

(3) Podvorica, F. I.; Combellas, C.; Delamar, M.; Kanoufi, F. A. A.; Pinson, J.

Spontaneous Grafting of Iron Surfaces by Reduction of Aryldiazonium Salts in Acidic Water: Applications to the Inhibition of Iron Corrosion. Passiv. Met. Semicond. Prop.

Thin Oxide Layers 2006, No. 9, 697-702. https://doi.org/10.1016/B978-0444522245/50106-2.

(4) Gooding, J. J. Advances in Interfacial Design for Electrochemical Biosensors and Sensors: Aryl Diazonium Salts for Modifying Carbon and Metal Electrodes. Electroanalysis 2008, 20 (6), 573-582. https://doi.org/10.1002/elan.200704124.

(5) Nxele, S. R.; Mashazi, P.; Nyokong, T. Electrode Modification Using Alkynyl Substituted Fe(II) Phthalocyanine via Electrografting and Click Chemistry for Electrocatalysis. Electroanalysis 2015, 27 (10), 2468-2478. https://doi.org/10.1002/elan.201500212.

(6) Assresahegn, B. D.; Brousse, T.; Bélanger, D. Advances on the Use of Diazonium Chemistry for Functionalization of Materials Used in Energy Storage Systems. Carbon N. Y. 2015, 92, 362-381. https://doi.org/10.1016/j.carbon.2015.05.030.

(7) Hetemi, D.; Noël, V.; Pinson, J. Grafting of Diazonium Salts on Surfaces: Application to Biosensors. Biosensors 2020, 10 (1), 4. https://doi.org/10.3390/bios 10010004.

(8) Combellas, C.; Kanoufi, F.; Pinson, J.; Podvorica, F. I. Sterically Hindered Diazonium Salts for the Grafting of a Monolayer on Metals. J. Am. Chem. Soc. 2008, 130 (27), 8576-8577. https://doi.org/10.1021/ja8018912.

(9) Greenwood, J.; Phan, T. H.; Fujita, Y.; Li, Z.; Ivasenko, O.; Vanderlinden, W.; Van Gorp, H.; Frederickx, W.; Lu, G.; Tahara, K.; Tobe, Y.; Uji-I, H.; Mertens, S. F. L.; De 
Feyter, S. Covalent Modification of Graphene and Graphite Using Diazonium

Chemistry: Tunable Grafting and Nanomanipulation. ACS Nano 2015, 9 (5), 55205535. https://doi.org/10.1021/acsnano.5b01580.

(10) Mattiuzzi, A.; Jabin, I.; Mangeney, C.; Roux, C.; Reinaud, O.; Santos, L.; Bergamini, J. F.; Hapiot, P.; Lagrost, C. Electrografting of Calix[4]Arenediazonium Salts to Form Versatile Robust Platforms for Spatially Controlled Surface Functionalization. Nat. Commun. 2012, 3:1130. https://doi.org/10.1038/ncomms2121.

(11) Nguyen, V. Q.; Sun, X.; Lafolet, F.; Audibert, J. F.; Miomandre, F.; Lemercier, G.; Loiseau, F.; Lacroix, J. C. Unprecedented Self-Organized Monolayer of a Ru(II) Complex by Diazonium Electroreduction. J. Am. Chem. Soc. 2016, 138 (30), 93819384. https://doi.org/10.1021/jacs.6b04827.

(12) Nielsen, L. T.; Vase, K. H.; Dong, M.; Besenbacher, F.; Pedersen, S. U.; Daasbjerg, K. Electrochemical Approach for Constructing a Monolayer of Thiophenolates from Grafted Multilayers of Diaryl Disulfides. J. Am. Chem. Soc. 2007, 129 (7), 1888-1889. https://doi.org/10.1021/ja0682430.

(13) Malmos, K.; Dong, M.; Pillai, S.; Kingshott, P.; Besenbacher, F.; Pedersen, S. U.; Daasbjerg, K. Using a Hydrazone-Protected Benzenediazonium Salt to Introduce a near-Monolayer of Benzaldehyde on Glassy Carbon Surfaces. J. Am. Chem. Soc. 2009, 131 (13), 4928-4936. https://doi.org/10.1021/ja809816x.

(14) Menanteau, T.; Levillain, E.; Breton, T. Electrografting via Diazonium Chemistry: From Multilayer to Monolayer Using Radical Scavenger. Chem. Mater. 2013, 25 (14), 2905-2909. https://doi.org/10.1021/cm401512c.

(15) Menanteau, T.; Levillain, E.; Downard, A. J.; Breton, T. Evidence of Monolayer Formation via Diazonium Grafting with a Radical Scavenger: Electrochemical, AFM 
and XPS Monitoring. Phys. Chem. Chem. Phys. 2015, 17 (19), 13137-13142. https://doi.org/10.1039/c5cp01401h.

(16) Pichereau, L.; López, I.; Cesbron, M.; Dabos-Seignon, S.; Gautier, C.; Breton, T. Controlled Diazonium Electrografting Driven by Overpotential Reduction: A General Strategy to Prepare Ultrathin Layers. Chem. Commun. 2019, 55 (4), 455-457. https://doi.org/10.1039/c8cc08331b.

(17) López, I.; Cesbron, M.; Levillain, E.; Breton, T. Diazonium Grafting Control through a Redox Cross-Reaction: Elucidation of the Mechanism Involved When Using 2,2Diphenylpicrylhydrazyl as an Inhibitor. ChemElectroChem 2018, 5 (8), 1197-1202. https://doi.org/10.1002/celc.201701331.

(18) Ceccato, M.; Bousquet, A.; Hinge, M.; Pedersen, S. U.; Daasbjerg, K. Using a Mediating Effect in the Electroreduction of Aryldiazonium Salts to Prepare Conducting Organic Films of High Thickness. Chem. Mater. 2011, 23 (6), 1551-1557. https://doi.org/10.1021/cm1033244.

(19) Baranton, S.; Bélanger, D. In Situ Generation of Diazonium Cations in Organic Electrolyte for Electrochemical Modification of Electrode Surface. Electrochim. Acta 2008, 53 (23), 6961-6967. https://doi.org/10.1016/j.electacta.2008.02.105.

(20) Shkirskiy, V.; Levillain, E.; Gautier, C. Capacitive Impedance for Following In-situ the Grafting Kinetics of Diazonium Salts. ChemPhysChem 2021, 22, 1074-1078. https://doi.org/10.1002/cphc.202100154.

(21) Alévêque, O.; Levillain, E.; Sanguinet, L. Spectroelectrochemistry on Electroactive Self-Assembled Monolayers: Cyclic Voltammetry Coupled to Spectrophotometry. Electrochem. commun. 2015, 51, 108-112. https://doi.org/10.1016/j.elecom.2014.12.014. 
(22) Alévêque, O.; Gautier, C.; Levillain, E. Real-Time Absorption

Spectroelectrochemistry: From Solution to Monolayer. Curr. Opin. Electrochem. 2019, 15, 34-41. https://doi.org/10.1016/j.coelec.2019.03.015.

(23) Amatore, C.; Klymenko, O.; Svir, I. A New Strategy for Simulation of Electrochemical Mechanisms Involving Acute Reaction Fronts in Solution: Application to Model Mechanisms. Electrochem. commun. 2010, 12 (9), 1165-1169. https://doi.org/10.1016/j.elecom.2010.06.008.

(24) Amatore, C.; Klymenko, O.; Svir, I. A New Strategy for Simulation of Electrochemical Mechanisms Involving Acute Reaction Fronts in Solution: Principle. Electrochem. commun. 2010, 12 (9), 1170-1173. https://doi.org/10.1016/j.elecom.2010.06.009.

(25) Bkhach, S.; Le Duc, Y.; Alévêque, O.; Gautier, C.; Hudhomme, P.; Levillain, E. Highly Stable Perylenediimide-Based Self-Assembled Monolayers Studied with Spectroelectrochemistry. ChemElectroChem 2016, 3 (6), 887-891. https://doi.org/10.1002/celc.201600034.

(26) Bkhach, S.; Alévêque, O.; Morille, Y.; Breton, T.; Hudhomme, P.; Gautier, C.; Levillain, E. Absorption Spectroelectrochemistry on Mixed Perylenediimide-Based Self-Assembled Monolayers: Non-Linear Dependence of Absorbance versus Surface Coverage. ChemElectroChem 2017, 4 (3), 601-606. https://doi.org/10.1002/celc.201600770.

(27) Haccoun, J.; Vautrin-U1, C.; Chaussé, A.; Adenier, A. Electrochemical Grafting of Organic Coating onto Gold Surfaces: Influence of the Electrochemical Conditions on the Grafting of Nitrobenzene Diazonium Salt. Prog. Org. Coatings 2008, 63 (1), 1824. https://doi.org/10.1016/j.porgcoat.2008.04.001.

(28) Bouden, S.; Pinson, J.; Vautrin-U1, C. Electrografting of Diazonium Salts: A Kinetics 
Study. Electrochem. commun. 2017, 81, 120-123.

https://doi.org/10.1016/j.elecom.2017.06.007.

(29) Zhang, X.; Rösicke, F.; Syritski, V.; Sun, G.; Reut, J.; Hinrichs, K.; Janietz, S.; Rappich, J. Influence of the Para-Substitutent of Benzene Diazonium Salts and the Solvent on the Film Growth during Electrochemical Reduction. Zeitschrift fur Phys.

Chemie 2014, 228 (4-5), 557-573. https://doi.org/10.1515/zpch-2014-0450.

(30) Tanaka, M.; Sawaguchi, T.; Sato, Y.; Yoshioka, K.; Niwa, O. Surface Modification of GC and HOPG with Diazonium, Amine, Azide, and Olefin Derivatives. Langmuir 2011, 27 (1), 170-178. https://doi.org/10.1021/la1035757.

(31) Adenier, A.; Combellas, C.; Kanoufi, F.; Pinson, J.; Podvorica, F. I. Formation of Polyphenylene Films on Metal Electrodes by Electrochemical Reduction of Benzenediazonium Salts. Chem. Mater. 2006, 18 (8), 2021-2029. https://doi.org/10.1021/cm052065c.

(32) Dias, M.; Hudhomme, P.; Levillain, E.; Perrin, L.; Sahin, Y.; Sauvage, F. X.; Wartelle, C. Electrochemistry Coupled to Fluorescence Spectroscopy: A New Versatile Approach. Electrochem. commun. 2004, 6 (3), 325-330. https://doi.org/10.1016/j.elecom.2004.01.010.

(33) Munteanu, S.; Roger, J. P.; Fedala, Y.; Amiot, F.; Combellas, C.; Tessier, G.; Kanoufi, F. Mapping Fluxes of Radicals from the Combination of Electrochemical Activation and Optical Microscopy. Faraday Discuss. 2013, 164, 241-258. https://doi.org/10.1039/c3fd00024a.

(34) Bhugun, I.; Savéant, J. M. Derivatization of Surfaces and Self-Inhibition in Irreversible Electrochemical Reactions: Cyclic Voltammetry and Preparative-Scale Electrolysis. J. Electroanal. Chem. 1995, 395 (1-2), 127-131. https://doi.org/10.1016/0022- 
0728(95)04145-E.

(35) Savéant, J. M. Electron Transfer, Bond Breaking and Bond Formation. In Advances in Physical Organic Chemistry; 2000; Vol. 35, pp 117-192.

https://doi.org/10.1016/s0065-3160(00)35013-4.

(36) Andrieux, C. P.; Pinson, J. The Standard Redox Potential of the Phenyl Radical/Anion Couple. J. Am. Chem. Soc. 2003, 125 (48), 14801-14806.

https://doi.org/10.1021/ja0374574.

(37) Combellas, C.; Kanoufi, F.; Pinson, J.; Podvorica, F. I. Time-of-Flight Secondary Ion Mass Spectroscopy Characterization of the Covalent Bonding between a Carbon Surface and Aryl Groups. Langmuir 2005, 21 (1), 280-286.

https://doi.org/10.1021/la0481061.

(38) Delamar, M.; Hitmi, R.; Pinson, J.; Savéant, J. M. Covalent Modification of Carbon Surfaces by Grafting of Functionalized Aryl Radicals Produced from Electrochemical Reduction of Diazonium Salts. J. Am. Chem. Soc. 1992, 114 (14), 5883-5884.

(39) Branchi, B.; Galli, C.; Gentili, P. Reactivity of Aryl and Vinyl Radicals: Abstraction of Hydrogen Atom or Reaction with a Nucleophile. European J. Org. Chem. 2002, No. 16, 2844-2854. https://doi.org/10.1002/1099-0690(200208)2002:16<2844::AIDEJOC2844>3.0.CO;2-9. 
TOC Graphic

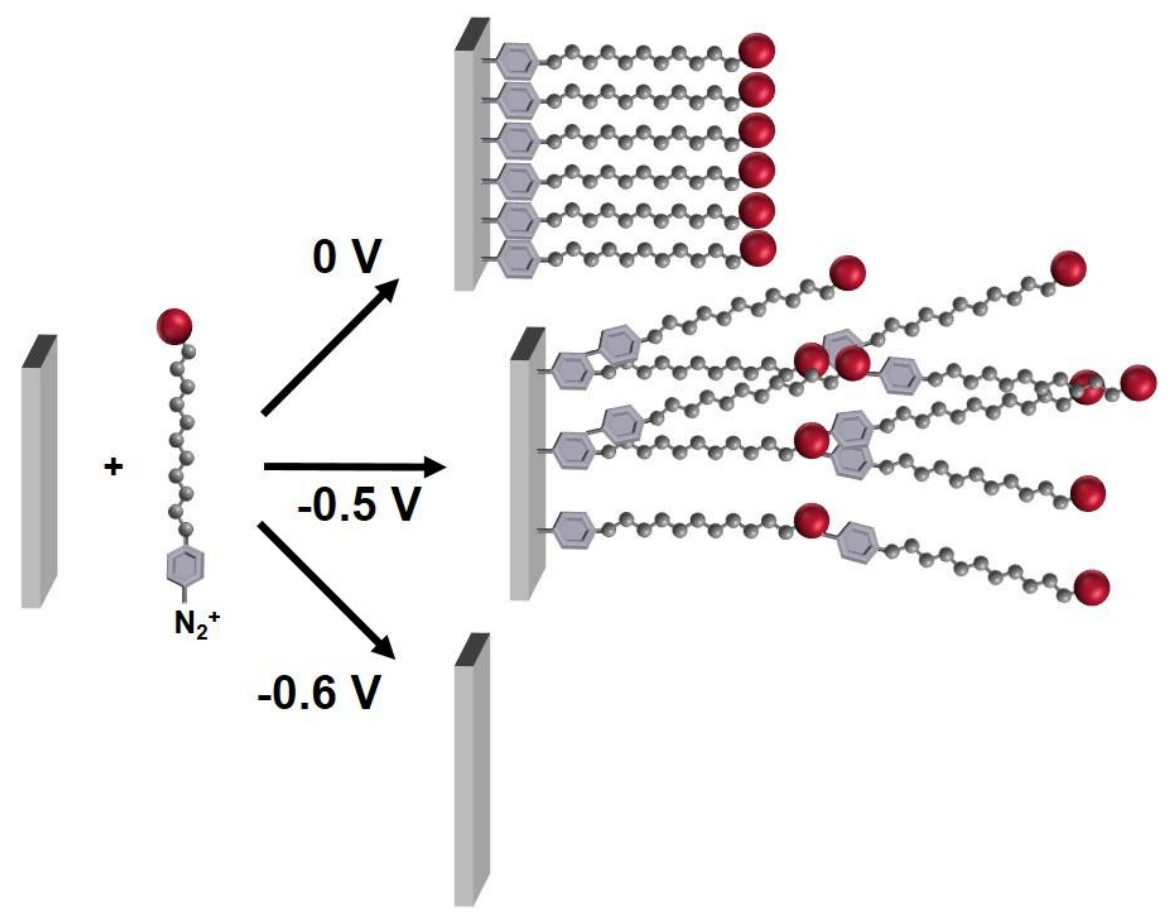

